\title{
La zonificación del riesgo en salud: la fiebre amarilla desde una perspectiva geográfica en La Macarena, departamento del Meta, Colombia
}

\author{
Health risk zoning: yellow fever from a geographical \\ perspective in La Macarena, Department of Meta, \\ Colombia
}

${ }^{1}$ Biólogo, Especialista en Epidemiología, Magíster en Geografía. Investigador, Ecodatum S.A.S., Bogotá, Colombia. $\triangle$ iD

Larry Niño

RESUMEN En este trabajo se zonifica el riesgo de fiebre amarilla en La Macarena (departamento del Meta, Colombia), en función de amenazas ambientales y vulnerabilidades socioeconómicas. Se realizó un estudio ecológico en el que se integraron, en un sistema de información geográfica, datos publicados entre 2007 y 2013 sobre las condiciones del municipio. A través de superposición de capas cartográficas se obtuvieron magnitudes de amenaza y vulnerabilidad proporcionales al grado de severidad. Como resultado se describe la heterogeneidad espacial del riesgo de fiebre amarilla, la cual sugiere que las áreas circundantes a centros poblados, vías y ríos presentan la mayor probabilidad de transmisión. Se concluye que la representación cartográfica de la distribución espacial del riesgo en el municipio constituye un aporte metodológico a la zonificación de riesgos en salud, en espacios geográficos concretos y en función de amenazas y vulnerabilidades, lo cual facilita la toma de decisiones en salud pública.

PALABRAS CLAVES Mapa de Riesgo; Vulnerabilidad en Salud; Amenazas; Zonificación; Geografía Médica; Fiebre Amarilla; Colombia.

\begin{abstract}
This paper attempts to zone yellow fever risk in La Macarena (department of Meta, Colombia) in terms of environmental hazards and socio-economic vulnerabilities. An ecological study was carried out, in which data published from 2007 to 2013 on conditions of the municipality were integrated into a geographic information system. Through a superposition of map layers, magnitudes of hazard and vulnerability proportional to the degree of severity were obtained. As a result the spatial heterogeneity of the risk of yellow fever was described, suggesting that the areas surrounding populated centers, roads and rivers present the highest probability of transmission. It is concluded that the cartographic representation of the spatial distribution of risk in the municipality constitutes a methodological contribution to health risk zoning - in concrete geographical areas and based on hazards and vulnerabilities - which facilitates decision-making in public health.
\end{abstract}

KEY WORDS Risk Map; Health Vulnerability; Hazards; Zoning; Geography, Medical;

Yellow Fever; Colombia. 


\section{INTRODUCCIÓN}

La relación entre la geografía y la salud se ha reconocido desde la Antigua Grecia, las teorías hipocráticas derivadas de la observación de los aires y las aguas donde las personas se asentaban o deambulaban, buscaban establecer su influencia en la salud de la población ${ }^{(1)}$. Sin embargo, recién en la década de 1970 fue sugerida la geografía del bienestar como una nueva organización de la geografía humana, que propuso un enfoque integrador entre las disciplinas geográficas y el bienestar humano. El espacio como objeto de estudio es común a la epidemiología y la geografía; además, el análisis de distribuciones espaciales permite relacionar eventos en salud y atributos ambientales, sociales o económicos. Por consiguiente, la geografía médica es hoy considerada como la aplicación del conocimiento geográfico, sus métodos y técnicas a la investigación en salud de acuerdo a dos subdivisiones: la nosogeografía, que identifica y analiza patrones de distribución espacial de eventos en salud, y la geografía de la atención en salud, la cual se ocupa de la planificación y distribución de recursos en el sistema de atención médica ${ }^{(2)}$. Asimismo, la cartografía es un medio para la organización, análisis y presentación de información que soporta la teoría de que los eventos en salud se relacionan con variables socioeconómicas y geográficas desde una perspectiva ecológica y multifactorial ${ }^{(3)}$. El objeto de estudio aquí considerado es la vereda, un espacio discreto que divide al municipio y que conforma la unidad social, económica y territorial por relaciones de proximidad y medios de desarrollo de la población que, a su vez, corresponde a una categoría de síntesis y convergencia en la que se expresan diversos procesos involucrados en las condiciones de salud de la población ${ }^{(4)}$.

La investigación de las enfermedades transmitidas por vectores (ETV) es compleja, puesto que busca vincular el agente etiológico, el huésped intermediario o reservorio y al hombre en un contexto ambiental; además los análisis espaciales se consolidan como complemento de la investigación ecológica y epidemiológica ${ }^{(5)}$. El estudio de las ETV debe ser abordado desde una perspectiva ecológica, donde los ecosistemas locales que albergan los hábitats de los vectores y hospederos o reservorios que facilitan la transmisión de las enfermedades adquieren relevancia geográfica. Además de las condiciones ambientales, las actividades humanas juegan un papel preponderante en la distribución espacial de las ETV, particularmente, el uso del suelo, la explotación maderera, las actividades agropecuarias y la construcción de infraestructuras. La dimensión geográfica de estos atributos ha hecho que los sistemas de información geográfica (SIG), entendidos como un conjunto de herramientas que recolectan, almacenan, extraen, transforman y despliegan datos espaciales, se hayan constituido en un importante recurso para el estudio de la distribución del riesgo, vigilancia y focalización de acciones de prevención y control de las ETV(6).

En la evaluación de situaciones en salud, es de especial importancia el desarrollo de indicadores idóneos para estimar condiciones de riesgo originados en condiciones ambientales y sociales ${ }^{(4)}$; el riesgo se define como la probabilidad de ocurrencia de un evento bajo ciertas circunstancias en un periodo de tiempo definido, el cual resulta en pérdidas económicas o sociales, su estimación es función de la amenaza o fuente de peligro y de la vulnerabilidad o propensión a daños ${ }^{(7,8)}$. En el caso de la fiebre amarilla, la amenaza está asociada al hábitat del vector y los hospederos o reservorios del virus, mientras que la vulnerabilidad se relaciona con la distribución de la población humana, su estado inmunológico y las actividades económicas ${ }^{(5)}$. El objetivo del presente trabajo fue presentar la zonificación del riesgo de fiebre amarilla en La Macarena, en función de amenazas y vulnerabilidades, lo cual busca responder a necesidades que faciliten la toma de decisiones en salud pública. A su vez, como hipótesis, se procuró exponer la aplicabilidad de los SIG como método idóneo para la evaluación de los riesgos en salud, particularmente, en un análisis espacial de información 
secundaria de las condiciones sociales, económicas y ambientales del municipio.

\section{El contexto de la fiebre amarilla}

La fiebre amarilla es una infección viral zoonótica que perdura en hábitats silvestres gracias a mosquitos de los géneros Haemagogus spp. y Sabethes spp., los cuales se desarrollan y reproducen en el dosel de los bosques, donde se alimentan de diferentes poblaciones de primates no humanos; aunque es común que estos insectos desciendan al sotobosque o claros del bosque para alimentarse de personas que generalmente desarrollan actividades agrícolas, ganaderas o extractivas; quienes son vulnerables a la enfermedad si no están protegidas por la vacuna antiamarílica. Los monos que presentan mayor susceptibilidad al virus de la fiebre amarilla y que están presentes en la zona de estudio son los araguatos (Alouatta seniculus). Sin embargo, los monos araña (Saymiri spp.), los monos ardilla (Ateles sp.) y los monos lechuza (Aotus trivirgatus), son afectados por la infección, aunque con menor intensidad ${ }^{(9)}$. A su vez, la presencia de altas densidades del mosquito Aedes aegypti en centros poblados ubicados en áreas enzoóticas de esta enfermedad constituye un riesgo potencial de su urbanización ${ }^{(10)}$. A pesar de la existencia de una vacuna, la fiebre amarilla es una causa importante de morbimortalidad en la región tropical y subtropical de Suramérica, donde se registran 300 casos anuales, principalmente entre agricultores, viajeros, practicantes de ecoturismo e inmigrantes. Se estima que, en Colombia, cinco millones de personas habitan territorios selváticos con condiciones favorables para la transmisión del virus, particularmente el piedemonte de las cordilleras central y oriental, la cuenca de los ríos Magdalena, Orinoco, Atrato y Catatumbo; y las estribaciones de la Sierra Nevada de Santa Marta ${ }^{(5,11)}$.

Aunque los beneficios del turismo a las economías locales y regionales pueden ser significativos, es precario el conocimiento acerca de los efectos de esta actividad sobre los habitantes de zonas turísticas y sus visitantes. La ubicación geográfica y las características ecológicas, ambientales, urbanísticas y demográficas son factores determinantes de las condiciones de salubridad de los destinos turísticos, donde el tránsito de viajeros puede convertirlos en agentes propagadores de agentes infecciosos, incluyendo las ETV, puesto que los turistas son altamente susceptibles a estas enfermedades, dada la naturaleza endémica de los destinos visitados. La planificación del viaje turístico debe incluir información sobre inmunizaciones y comportamientos que busquen prevenir la transmisión o el contagio de enfermedades sin inducir alarma o predisponer negativamente al turista ${ }^{(12)}$.

A pesar de su potencial ambiental y ecoturístico, el Parque Nacional de La Sierra de La Macarena es uno de los tres parques nacionales naturales más afectados por cultivos de coca, en los que la dinámica de establecimiento y abandono de cultivos ilícitos está asociada a la ruralización como proceso de transformaciones antrópicas de los espacios naturales. El frente de colonización que combina deforestación, cambios de cobertura del suelo por pastos para ganadería y cultivos de subsistencia e ilícitos avanza a través de hidrografía vulnerable y la presencia de bosques de tierra firme, los cuales constituyen nuevas áreas para el establecimiento de estas actividades ${ }^{(13)}$. En la actualidad, existe evidencia de que el desplazamiento de personas susceptibles, hacia zonas endémicas con transmisión activa de fiebre amarilla, para realizar actividades relacionadas con la producción de cultivos ilícitos, está asociado a brotes de esta enfermedad febril ${ }^{(14)}$.

\section{El espacio geográfico de La Macarena}

La zona de estudio corresponde al municipio de La Macarena, localizado al sur del departamento del Meta, en una zona donde confluyen ecosistemas andinos, orinocenses y amazónicos. Registra temperaturas medias que oscilan entre $23^{\circ} \mathrm{C}$ y $35^{\circ} \mathrm{C}$, con una media anual de $29^{\circ} \mathrm{C}$; el régimen pluviométrico es 
monomodal de $2.000 \mathrm{~mm}$ promedio anual, el cual se incrementa gradualmente de este a oeste hacia la Sierra de la Macarena, donde alcanza hasta $4.000 \mathrm{~mm}$, los mayores montos de precipitación se registran entre abril y septiembre $^{(15)}$. Los $11.231 \mathrm{~km}^{2}$ de la zona de estudio hacen parte del Área de Manejo Especial de La Macarena (AMEM), donde se incluyen los parques nacionales naturales de La Sierra de La Macarena y Tinigua, los cuales ocupan el $14,5 \%$ del área del municipio. Los centros poblados se han conformado en las riberas de los afluentes principales, particularmente, en los ríos Guayabero, Losada y Tunia, y en la vía que conduce hacia San Vicente del Caguán, promovidos por las dinámicas comerciales rurales originadas por el cultivo de la coca desde la década de 1970 y la articulación de medios de transporte fluvial $y$ terrestre ${ }^{(16,17)}$.

La Macarena se divide en 156 veredas, las cuales presentan un área de $6.848,4$ ha en promedio, las veredas de mayor extensión corresponden a Yaguara y San José de Caquetania con $105.659,9$ ha y $102.929,2$ ha, respectivamente. La población se estima en 31.928 personas para 2014, según información del Departamento Administrativo Nacional de Estadística (DANE), de las cuales el $86,2 \%$ corresponde a población rural dedicada, principalmente, a actividades extractivas y agropecuarias de autoconsumo, y se presume una alta proporción de población flotante, relacionada con la industria del narcotráfico. La densidad poblacional del municipio se concentra en las riberas de los ríos Losada y Guayabero y, particularmente, en las veredas Altamira, El Centro, La Unión I, Los Pinos, Pailas, Playa Rica, San Juan de Lozada y Villa Rica con más de siete habitantes $/ \mathrm{km}^{2(18,19,20)}$.

La mitad de los centros poblados cuenta con centros de salud, entre los que se destaca el ubicado en la cabecera municipal que cuenta con servicios de baja complejidad que incluyen consulta médica, urgencias, laboratorio clínico, rayos $\mathrm{X}$ y odontología. La atención en los demás centros de salud es de carácter básica, su infraestructura es deficiente y presentan intermitencia en la prestación de servicios debido a la escasez de dotación y personal médico ${ }^{(18)}$. Las veredas que cuentan con centros médicos dentro de su territorio siguen el mismo patrón de densidad de poblamiento, y corresponden a La Catalina, Altamira, La Cristalina y San Juan de Losada sobre los ríos Guayabero y Losada; Alto Morrocoy, La Sombra y Los Pozos en la vía principal a San Vicente del Caguán, y San José de Caquetania sobre el río Tunia. Durante la última década, particularmente a fines de 2008 y principios de 2009 , se presentó un brote de fiebre amarilla en el municipio de La Macarena, en el cual se registraron cuatro casos confirmados: tres hombres y una mujer entre los 17 y 23 años de edad ${ }^{(21)}$; las veredas que presentaron evidencia de transmisión correspondieron a El Diamante, Las Delicias II y Altamira.

La oferta ambiental, paisajística y acuícola genera potencial ecoturístico en el municipio, como en Caño Cristales y otros afluentes del río Guayabero ${ }^{(16)}$, donde son atraídos cientos de turistas nacionales y extranjeros anualmente, en particular, al Parque Nacional Natural de la Sierra de La Macarena y las veredas La Cachivera, Alto y Bajo Raudal, La Florida II, Altamira y Aguazul. Otra actividad económica, aunque de naturaleza ilegal, que atrae población migrante, es el cultivo de la coca. Esta actividad ilícita, entre 2010 y 2013, abarcaba un área de 57.106,5 ha en la zona de estudio, que corresponden al $5,1 \%$ del municipio, caracterizada por paisajes de la región amazónica de suelos bien drenados, fuertemente ácidos y de baja fertilidad. Estos cultivos ilícitos se concentran en la región comprendida entre las estribaciones orientales de la Sierra de La Macarena y el río Guayabero, especialmente, dentro del Parque Nacional Natural de la Sierra de la Macarena, donde han sido influenciadas por cultivos de coca $12.816,8$ ha $^{(13,18,20,22,23,24)}$. El $20,5 \%$ de las veredas tienen áreas afectadas por el cultivo ilícito, en particular, la vereda Tres Chorros con el $71,4 \%$ de su territorio, seguido por El Diamante con el $67,0 \%$ y La Unión II con el 56,1\%.

En cuanto a las condiciones climáticas de la zona de estudio, el 99,4\% del área 
tiene un clima cálido húmedo, que abarca la totalidad de las 156 veredas, mientras que el área restante presenta clima templado húmedo. La vereda con mayor proporción de área con clima templado húmedo corresponde a Alto Losada con el 9,7\%, seguida por Guaduas con el 4,0\%, Brisas del Losada con un $2,4 \%$ y Las Américas con el 1,7\%; el Parque Nacional Natural de la Sierra de la Macarena cuenta con $6.078,0$ ha de clima templado húmedo en las estribaciones occidentales de la Sierra de La Macarena dentro del municipio. De acuerdo a las coberturas, en La Macarena los bosques ocupan un $66,2 \%$ del área, y se definen como comunidades vegetales dominadas por árboles de alturas superiores a 5,0 $\mathrm{m}$ y densidad de copas superior al $70,0 \%$. Esta cobertura se presenta en la totalidad de las veredas consideradas, en las que el $23,1 \%$ están ocupadas en una proporción mayor al 90,0\% por bosques. Los pastos introducidos para ganadería, que ocupan el $15,9 \%$ del área del municipio, se ubican principalmente al costado oeste en correspondencia con el frente de colonización proveniente de San Vicente del Caguán y alrededor de la cabecera municipal; el 11,5\% de las veredas están ocupadas por pastos en más del 70,0\% de su territorio, en particular, las veredas La Esmeralda I y La Aurora con un $97,0 \%$ y $93,6 \%$, respectivamente. Los herbazales corresponden a áreas en las que predomina la vegetación sin estructura de tallo definida y de altura no superior a $2 \mathrm{~m}$, principalmente, compuesta de gramíneas; se localizan en especial al costado sur, y abarcan el $13,3 \%$ del área del municipio y el $14,1 \%$ de las veredas, en particular, la Esperanza II y San José de Caquetania con el $90,7 \%$ y el $72,7 \%$ de su territorio, respectivamente. El 8,4\% del área del Parque Nacional Natural de la Sierra de La Macarena en el municipio tiene este tipo de cobertura en sus estribaciones. Los arbustales están constituidos por plantas leñosas perennes, con ramificaciones desde su base y que no sobrepasan los $5 \mathrm{~m}$ en su madurez, ocupan el 3,3\% del área del municipio, y están restringidos al Parque Nacional Natural de la Sierra de La Macarena y sus alrededores, donde el 32,5\% de su área en el municipio son arbustales. Esta cobertura se presenta, además, en un $4,5 \%$ de las veredas, sobre todo en Bajo Raudal, con un 32,3\% de su territorio, y en Cachivera, con un $29,6 \%$. La vegetación secundaria, que corresponde a etapas de sucesión arbustivas o arbóreas posteriores a procesos de deforestación, se encuentra principalmente a los costados de los principales ríos que facilitan la colonización y las actividades extractivas, ocupando el $0,7 \%$ del área de estudio y el $26,3 \%$ de las veredas, en especial Yarumales con el 21,0\% de su territorio, seguida por El Carmen con el $19,5 \%$ y Peña Roja con el 17,1\%. Los cultivos anuales abarcan el 0,5\% del área del municipio, localizados al costado oeste, en correspondencia con el frente de colonización proveniente de San Vicente del Caguán, esta cobertura está presente en el $19,2 \%$ de las veredas, en particular, El Dijen y Palmeras con el $32,9 \%$ y el $17,0 \%$ de sus territorios, respectivamente ${ }^{(22)}$.

\section{METODOLOGÍA}

Se realizó un estudio ecológico basado en un análisis espacial con información secundaria de las condiciones sociales, económicas y ambientales del municipio de La Macarena. En una primera fase, se realizó la recopilación y validación de la información cartográfica con la cual se estructuró un sistema de información geográfica, previa articulación, homologación y unificación de las capas en formatos vectorial y matricial a una escala de 1:100.000 en el sistema de proyección transversal de Mercator, datum SIRGAS y Zona Bogotá. La información cartográfica básica correspondiente al área municipal, vías, centros poblados, polígonos veredales e información temática de las áreas con potencial turístico, densidad poblacional e infraestructura en salud se obtuvo del Esquema de Ordenamiento Territorial (EOT) del municipio $^{(18)}$; los datos correspondientes a veredas con transmisión de fiebre amarilla ${ }^{(21)}$ procede del Instituto Nacional de Salud (INS); la información de cultivos ilícitos ${ }^{(13,23,24,25)}$ se obtuvo 
de los informes de la Oficina de las Naciones Unidas contra la Droga y el Delito (UNODC); finalmente, las coberturas del suelo, áreas climáticas e hidrografía se tomaron de las capas cartográficas del mapa de ecosistemas ${ }^{(22)}$ realizadas por el Sistema de Información Nacional Ambiental (SINA).

La probabilidad de encontrar asentamientos humanos o la localización de actividades propias de los medios de vida de pobladores locales como la caza, la pesca o labores agropecuarias de subsistencia, es inversa a la distancia a vías y cuerpos de agua, es decir que comúnmente se encuentran cercanos a estos elementos del territorio; asimismo, los centros poblados congregan personas alrededor de infraestructuras y equipamientos, incrementando la vulnerabilidad por focalización de personas expuestas ${ }^{(8)}$. De acuerdo a lo anterior y a los criterios de vulnerabilidad consignados en el Cuadro 1 , se trazaron áreas de influencia o buffers en los ríos principales, a una distancia de $2,0 \mathrm{~km}$, a $1,0 \mathrm{~km}$ en los centros poblados y a 2,0 km de la cabecera municipal; en las vías se trazaron de acuerdo a la frecuencia de tránsito, a 2,0 $\mathrm{km}$ en la vía principal, a $1,5 \mathrm{~km}$ en las vías secundarias y trocha ganadera, y a 1,0 km en las terciarias.

A continuación, la información geográfica documental en formato vectorial, representada por formas geométricas a manera de polígonos, fue transformada al formato matricial, el cual se constituye de pixeles o celdas con valores numéricos asociados; las variables consideradas se llevaron a un mismo tamaño de píxel de $30 \mathrm{~m}$, acorde con la escala de trabajo establecida, lo cual facilitó las operaciones posteriores realizadas con estas capas cartográficas. En síntesis, los antecedentes veredales de transmisión de fiebre amarilla y las variables ambientales relacionadas con el hábitat de los mosquitos vectores y los reservorios silvestres, correspondientes al clima y la cobertura vegetal, caracterizaron la amenaza; mientras que las variables socioeconómicas relacionadas con la densidad de población, los asentamientos humanos en los que se registra $A$. aegypti, el tránsito de personas por vías terrestres y fluviales, las actividades de pesca en ríos y caza en áreas de influencia fluvial, las áreas de actividad turística, el uso del suelo en actividades agropecuarias o extractivas de naturaleza lícita e ilícita y el acceso a servicios de salud, definieron la vulnerabilidad. Amenazas y vulnerabilidades se clasificaron en una escala numérica ordinal arbitraria del uno al cuatro, proporcional al grado de asociación directa a la probabilidad de transmisión viral, salvo la capacidad de respuesta a eventuales brotes, representada por la presencia de centros de salud, y correspondientes a las categorías bajo, medio, alto y muy alto, de acuerdo a los criterios del Cuadro 1. Luego, la superposición de las capas cartográficas matriciales permitió realizar la sumatoria de los valores asignados y contenidos en la matriz de datos para obtener capas con las magnitudes globales de amenaza y vulnerabilidad por separado. La integración de estos dos factores permitió establecer las unidades espaciales de riesgo epidemiológico, el cual fue estimado con una nueva superposición y producto de las magnitudes globales de amenaza y vulnerabilidad. Finalmente, se realizó una clasificación de la nueva capa obtenida en cuatro clases distintas, correspondientes al nivel de transmisibilidad viral de acuerdo a los factores anteriormente descritos, con el método intervalo geométrico, el cual realiza agrupamientos de acuerdo a intervalos de series geométricas, minimizando la suma de los cuadrados del número de elementos en cada clase y asegurando un número de valores similar en los rangos ${ }^{(26)}$. La rasterización y operaciones con las capas cartográficas se realizaron en el software QGIS 2.0.1, la clasificación de variables y montaje cartográfico en ArcMap 10.1.

\section{RESULTADOS}

De acuerdo al modelo, el $33,4 \%$ del área de La Macarena presenta vulnerabilidad media a la fiebre amarilla, en particular, al sureste del municipio y alrededor del Parque Nacional Natural Tinigua, donde el $6,4 \%$ de 
Cuadro 1. Valoración de vulnerabilidades y amenazas de fiebre amarilla en La Macarena, departamento del Meta, Colombia.

\begin{tabular}{|c|c|c|c|c|}
\hline & VARIABLE & CRITERIO & ATRIBUTO & VALORACIÓN \\
\hline \multirow{18}{*}{ 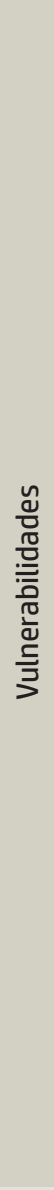 } & \multirow{4}{*}{$\begin{array}{l}\text { Densidad poblacional } \\
\text { veredal (habitantes } / \mathrm{km}^{2} \text { ) }\end{array}$} & \multirow{4}{*}{$\begin{array}{l}\text { Personas potencialmente vulnerables a la } \\
\text { transmisión viral de acuerdo a veredas }\end{array}$} & $<1$ & 1 - Baja \\
\hline & & & $1-4$ & 2-Media \\
\hline & & & $5-7$ & 3-Alta \\
\hline & & & $>7$ & 4-Muy Alta \\
\hline & \multirow{2}{*}{$\begin{array}{l}\text { Centros poblados y áreas de } \\
\text { influencia }\end{array}$} & \multirow{2}{*}{$\begin{array}{l}\text { Personas potencialmente vulnerables } \\
\text { a la transmisión viral de acuerdo a } \\
\text { aglomeración en centros poblados }\end{array}$} & Cabecera municipal & 4-Muy Alta \\
\hline & & & Otro asentamiento & 3-Alta \\
\hline & \multirow{2}{*}{ Centros de salud } & \multirow{2}{*}{ Accesibilidad a servicios de salud } & Presente en la vereda & 1 - Baja \\
\hline & & & Ausente en la vereda & 3-Alta \\
\hline & Hidrografía & $\begin{array}{l}\text { Personas potencialmente vulnerables a } \\
\text { la transmisión viral de acuerdo a tránsito } \\
\text { fluvial, asentamientos ribereños y } \\
\text { actividades de caza y pesca. }\end{array}$ & $\begin{array}{l}\text { Principales ríos navegables y } \\
\text { áreas de influencia }\end{array}$ & 3-Alta \\
\hline & \multirow{3}{*}{ Vías y áreas de influencia } & \multirow{3}{*}{$\begin{array}{l}\text { Personas potencialmente vulnerables a } \\
\text { la transmisión viral de acuerdo a tránsito } \\
\text { terrestre y asentamientos al margen de } \\
\text { vías }\end{array}$} & Vía principal & 4-Muy Alta \\
\hline & & & $\begin{array}{l}\text { Vía secundaria y trocha } \\
\text { ganadera }\end{array}$ & 3-Alta \\
\hline & & & Vía terciaria & 2-Media \\
\hline & \multirow{2}{*}{ Turismo } & \multirow{2}{*}{$\begin{array}{l}\text { Personas potencialmente vulnerables a la } \\
\text { transmisión viral de acuerdo a tránsito en } \\
\text { zonas turísticas }\end{array}$} & $\begin{array}{l}\text { Caño Cristales y área de } \\
\text { influencia }\end{array}$ & 4-Muy Alta \\
\hline & & & $\begin{array}{l}\text { Otras zonas con potencial } \\
\text { turístico y áreas de influencia }\end{array}$ & 3-Alta \\
\hline & Cultivos ilícitos & $\begin{array}{l}\text { Personas potencialmente vulnerables a la } \\
\text { transmisión viral de acuerdo a actividades } \\
\text { en zonas cocaleras }\end{array}$ & Áreas con influencia cocalera & 3-Alta \\
\hline & \multirow{3}{*}{ Uso del suelo } & \multirow{3}{*}{$\begin{array}{l}\text { Personas potencialmente vulnerables a la } \\
\text { transmisión viral de acuerdo a actividades } \\
\text { de explotación maderera y agropecuarias }\end{array}$} & Vegetación secundaria & 4-Muy Alta \\
\hline & & & Cultivos anuales o transitorios & 3-Alta \\
\hline & & & Pastos para ganadería & 2-Media \\
\hline \multirow{6}{*}{ 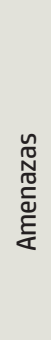 } & \multirow{2}{*}{ Clima } & \multirow{2}{*}{$\begin{array}{l}\text { Condiciones climáticas favorables al } \\
\text { establecimiento de vectores y hospederos } \\
\text { selváticos }\end{array}$} & Cálido húmedo & 3-Alta \\
\hline & & & Templado húmedo & 1 - Baja \\
\hline & \multirow{3}{*}{ Cobertura } & \multirow{3}{*}{$\begin{array}{l}\text { Condiciones de cobertura vegetal } \\
\text { favorables al establecimiento de vectores } \\
\text { y hospederos selváticos }\end{array}$} & Bosques naturales & 3-Alta \\
\hline & & & Arbustales & 2-Media \\
\hline & & & Herbazales & 1 - Baja \\
\hline & Fiebre amarilla & Antecedente de transmisión confirmado & $\begin{array}{l}\text { Veredas con transmisión de } \\
\text { fiebre amarilla }\end{array}$ & 4-Muy Alta \\
\hline
\end{tabular}

las veredas presentan una proporción mayor al $80,0 \%$ de su territorio bajo esta condición. La alta vulnerabilidad abarca el $31,1 \%$ del municipio, principalmente, en el frente de colonización proveniente de San Vicente del Caguán y en algunos corredores de transporte terrestre y fluvial. En el $7,7 \%$ de las veredas se observa este nivel de severidad en la vulnerabilidad en un área mayor al 70,0\% de su territorio. El 19,1\% de La Macarena presenta muy alta vulnerabilidad, en particular sobre el Río Guayabero y la vía principal que 
comunica a la cabecera municipal con San Vicente del Caguán, este atributo se presenta en una proporción mayor al $80,0 \%$ del territorio, en el $10,3 \%$ de veredas. Finalmente, la baja vulnerabilidad abarca el $17,0 \%$ del municipio, principalmente, en los Parque Nacional Natural de Tinigua y Sierra de la Macarena y, en particular, las veredas correspondientes a San José de Caquetania y La Catalina, las cuales presentan este grado de vulnerabilidad en un $58,7 \%$ y un $47,2 \%$ de su territorio, respectivamente (Figura 1).
Por su parte, el $66,2 \%$ del territorio del municipio que presenta alta amenaza de fiebre amarilla, corresponde a áreas boscosas de condiciones climáticas cálidas y húmedas, que constituyen los hábitats más favorables para el desarrollo de los insectos vectores y primates hospederos ${ }^{(5)}$. El $22,4 \%$ de sus veredas tiene este nivel de severidad en más del $90,0 \%$ de su territorio, principalmente alrededor del Parque Nacional Natural Tinigua y al este del municipio. Seguidamente, en el $17,3 \%$ del área de La Macarena se observa

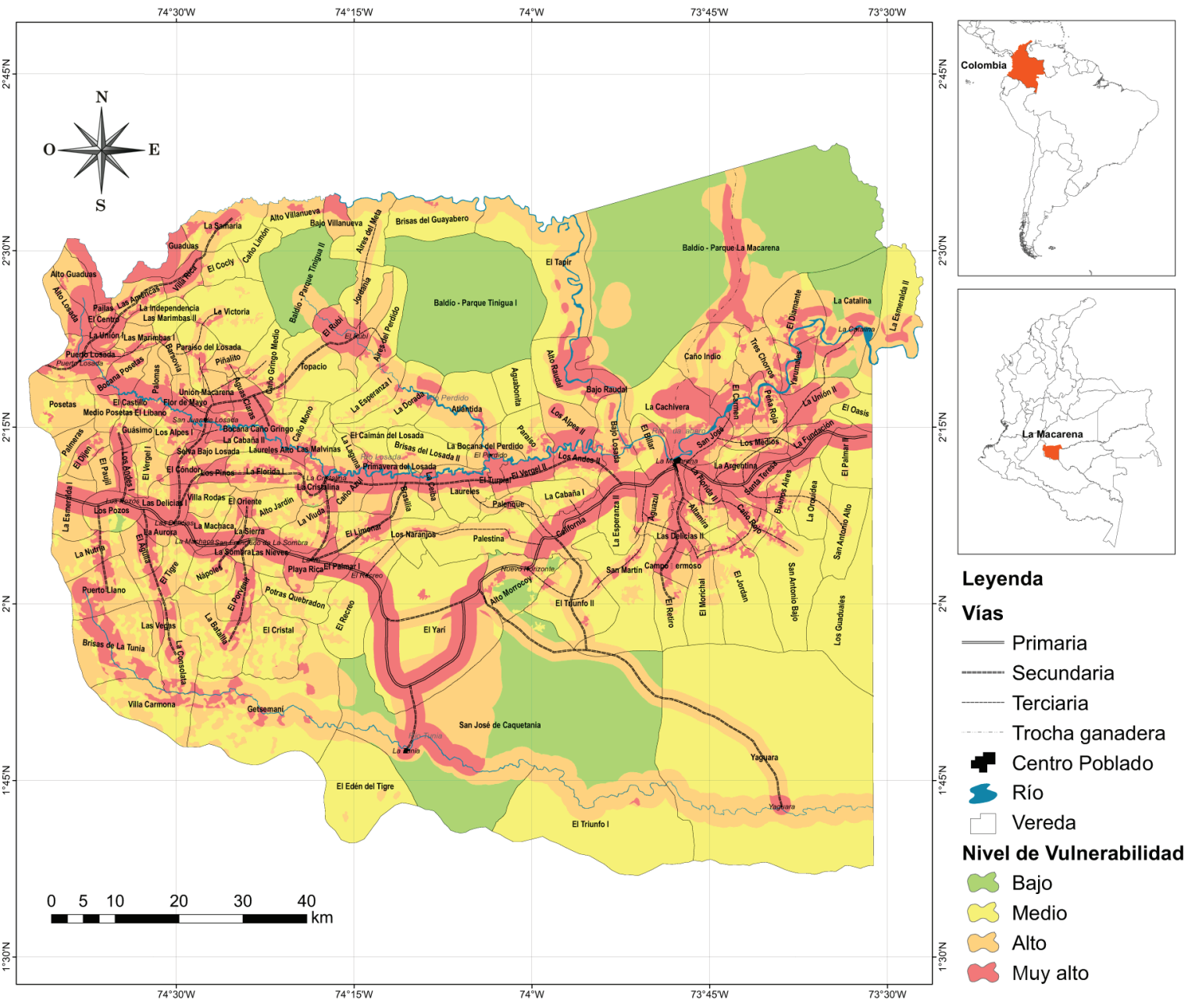

Figura 1. Nivel de vulnerabilidad a la fiebre amarilla en La Macarena, departamento del Meta, Colombia.

Fuente: Elaboración propia a partir de los datos provenientes del Esquema de Ordenamiento Territorial La Macarena (18), año 2008; de la Oficina de las Naciones Unidas contra la Droga y el Delito ${ }^{(13,23,24,25)}$, años 2011 a 2013; y del Sistema de Información Nacional Ambiental(22), año 2007. 
baja amenaza de fiebre amarilla, el 7,0\% de las veredas presenta este nivel de severidad en una proporción mayor al $80,0 \%$ de su territorio, particularmente en áreas con mayor influencia del frente de colonización proveniente del Caquetá y la cabecera municipal. La amenaza de nivel medio abarca el 16,1\% del área del municipio, principalmente, en el PNN Sierra de La Macarena y en inmediaciones del Medio Río Tunia y, en particular, las veredas correspondientes a La Esperanza II y San José de Caquetania, las cuales presentan esta severidad de amenaza en $90,7 \%$ y $72,7 \%$ de su territorio, respectivamente. Una amenaza muy alta se presenta en el 0,9\% de La Macarena, la máxima severidad se restringe a las veredas donde se ha registrado transmisión de fiebre amarilla, dado que reúnen las condiciones ecológicas para la coexistencia del vector y el reservorio silvestre para poner en circulación el virus, las cuales corresponden a El Diamante con el $83,4 \%$ de su territorio, Las Delicias II con el $77,9 \%$ y Altamira con el $52,2 \%$ del área bajo esta condición (Figura 2).

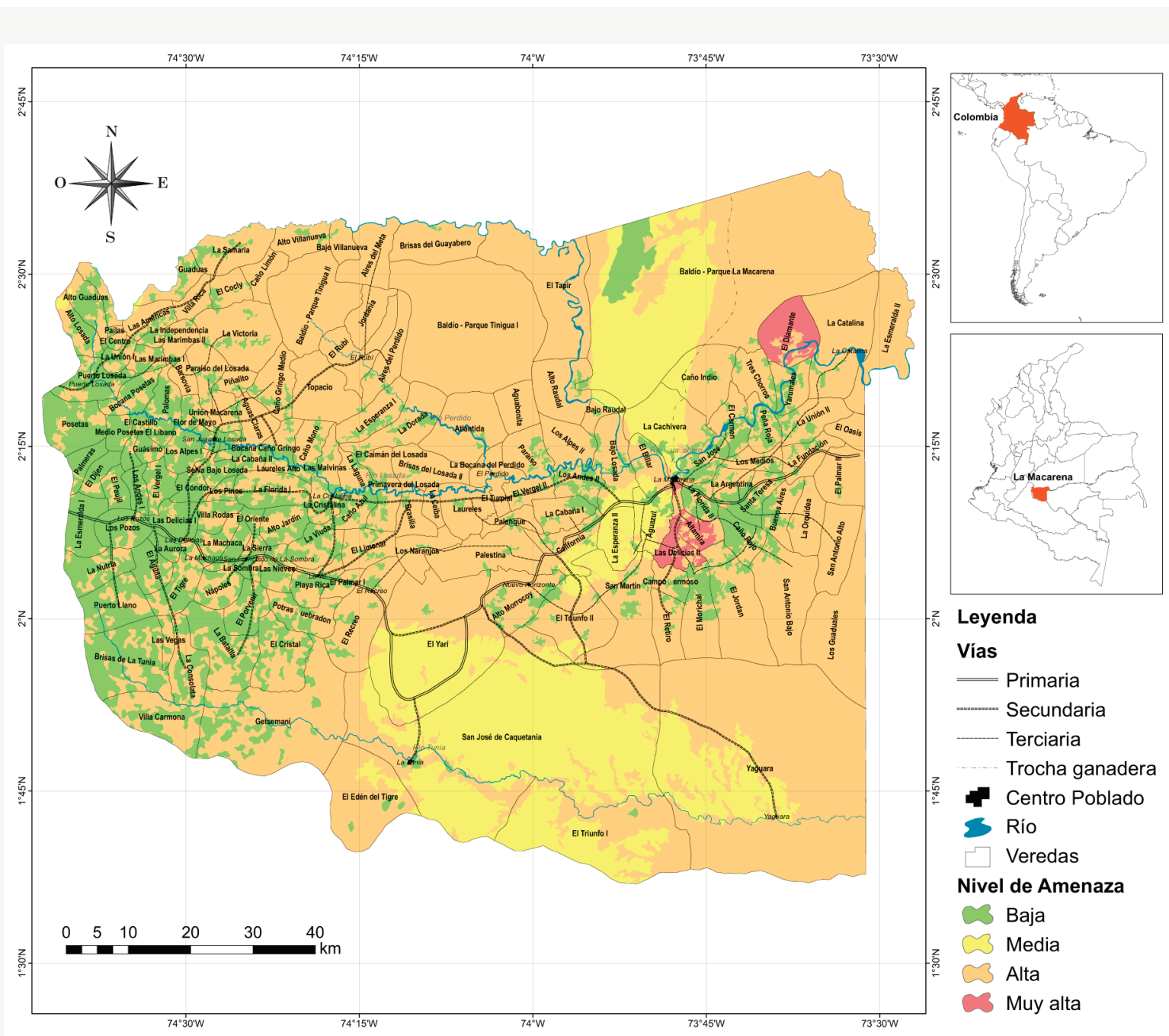

Figura 2. Amenaza de fiebre amarilla en La Macarena, departamento del Meta, Colombia.

Fuente: Elaboración propia a partir de los datos de Esquema de Ordenamiento Territorial La Macarena ${ }^{(18)}$, año 2008; del Sistema de Información Nacional Ambiental ${ }^{(22) \text {, }}$ año 2007; y del Instituto Nacional Salud ${ }^{(21)}$, año 2008. 
La conjunción de amenazas y vulnerabilidades resultó en la espacialización del riesgo (Figura 3). El 33,1\% del municipio se encuentra en riesgo medio de fiebre amarilla, principalmente, al costado suroeste y en torno al Parque Nacional Natural Tinigua; el 6,4\% de las veredas presentan esta severidad de riesgo en una proporción superior al 80,0\% de su territorio, en particular, Aguabonita y Los Guaduales con el $100 \%$ del área. El riesgo bajo abarca el 31,9\% de La Macarena, particularmente en la vereda San José de
Caquetania y los Parque Nacional Natural Tinigua y Sierra La Macarena; el riesgo alto se extiende por el $26,4 \%$ del municipio, principalmente, a lo largo de algunas vías secundarias y los ríos Guaduas, Tunia y Perdido, el $4,5 \%$ de las veredas presentan más del $70,0 \%$ de su territorio con esta severidad, donde sobresale Barsovia con el $98,7 \%$ de su área. Finalmente, el riesgo muy alto de fiebre amarilla abarca en el 9,2\% de La Macarena, en particular, zonas a lo largo de la vía principal y los ríos Losada y Guayabero, aquellas

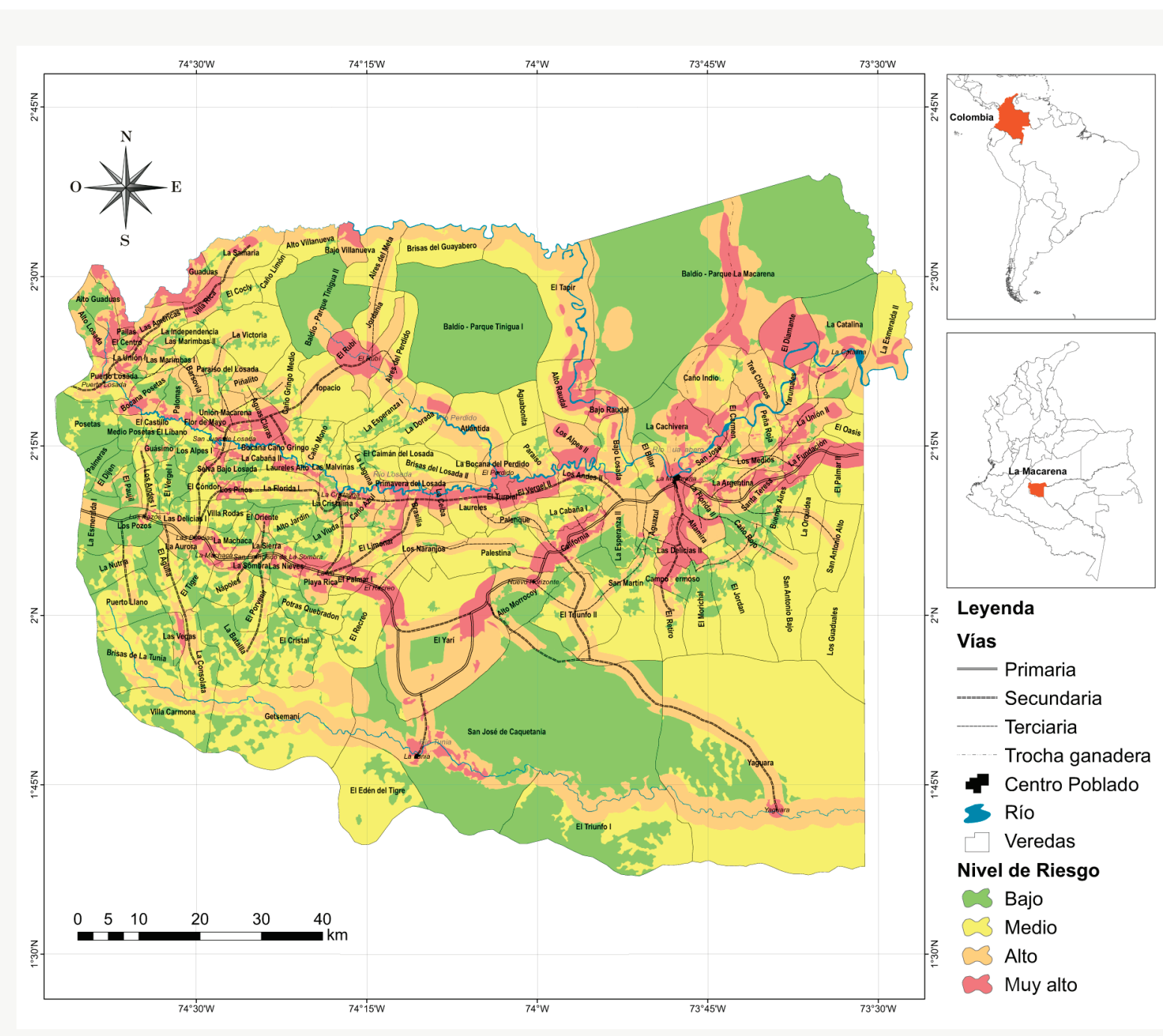

Figura 3. Riesgo de fiebre amarilla en La Macarena, departamento del Meta, Colombia.

Fuente: Elaboración propia a partir de los datos de vulnerabilidad y amenaza. 
veredas con antecedentes de transmisión viral e inmediaciones de la cabecera municipal; el 3,8\% de las veredas tiene esta condición de severidad en un área mayor al $70,0 \%$ de su territorio, sobresaliendo las veredas Las Delicias II y El Diamante con el $96,0 \%$ y $92,6 \%$ del área, respectivamente.

\section{DISCUSIÓN}

El uso del análisis espacial y la cartografía incrementan el conocimiento e interpretación de la distribución de eventos en salud, en la actualidad son significativamente importantes en la salud pública, dado que el $80,0 \%$ de las necesidades de información de quienes toman decisiones o definen políticas en gobiernos locales se relacionan con ubicaciones geográficas; la proximidad y complementariedad de los marcos conceptuales entre la salud y la geografía son evidentes, aunque la articulación de metodologías y técnicas de investigación están pobremente exploradas $^{(2)}$. Estas propuestas geográficas, en particular, la implementación de los sistemas de información geográfica, facilitan la toma de decisiones en salud pública, concretamente en el direccionamiento de recursos en la prevención, vigilancia y control tanto de vectores como de la transmisión ${ }^{(8,27,28)}$; estrategias de vacunación, capacitación de personal médico, fortalecimiento de la red hospitalaria ${ }^{(5)}$ y campañas educativas de prevención a la población local y turística ${ }^{(12)}$.

El presente trabajo constituye un aporte a la zonificación de riesgos en salud, al establecer la distribución espacial del riesgo epidemiológico de la fiebre amarilla en función de amenazas y vulnerabilidades, a escala de áreas veredales que expresan relaciones entre componentes y procesos socioeconómicos, ambientales y de las condiciones de salud de la población; más aún cuando Colombia está clasificada como país endémico con alto riesgo de infección, de acuerdo al mapa global de riesgo de fiebre amarilla -en concordancia con los criterios de transmisión de la Organización Mundial de la Salud (OMS) - donde la transmisión enzoótica es persistente, se registra la presencia de insectos vectores y primates hospederos y las infecciones son aún reportadas reiterativamente tanto en primates como en población humana ${ }^{(29)}$.

Una de las principales ventajas del enfoque presentado radica en que permite contrastar la información ecológica de vectores y hospederos silvestres con las condiciones de la población humana, puesto que una alta abundancia de vectores $\mathrm{u}$ hospederos silvestres no necesariamente representa un incremento en la magnitud de eventos epidemiológicos, y factores como la movilidad de los vectores, hábitats no frecuentados por personas, condiciones inmunológicas y comportamientos humanos diferenciales pueden influenciar directamente la exposición tanto a vectores como a patógenos ${ }^{(30)}$. Perspectivas metodológicas similares se han implementado en la realización de mapas de riesgo de la Fiebre del Valle del Rift en Senegal, donde la amenaza fue considerada como zonas potencialmente ocupadas por mosquitos, definidas por la precipitación y la localización de criaderos de los vectores, mientras que la vulnerabilidad fue concebida como aquellas zonas con presencia de rumiantes hospederos expuestos a las picaduras de los mosquitos ${ }^{(31)}$. Asimismo, un análisis multicriterio fue desarrollado para establecer la vulnerabilidad a la fiebre amarilla, a una escala espacial de distrito en Burkina Faso, con la estimación agregada de factores de exposición, definidos por atributos ecológicos y epidemiológicos, y factores de susceptibilidad, relacionados con el estado inmune de la población ${ }^{(32)}$.

En conclusión, la zonificación del riesgo de fiebre amarilla se evidencia como una aproximación metodológica para apoyar la planificación territorial en salud, corresponde a una herramienta multivariante en la que el acopio, el cruce y el análisis de la información de los antecedentes de transmisión, variables ambientales y atributos socioeconómicos han sido ponderados integradamente como criterios, de acuerdo a niveles de amenaza y vulnerabilidad, permitiendo establecer una valoración del riesgo en escala ordinal. 
La disponibilidad de información espacial, correspondiente a los factores de riesgo a escalas apropiadas, es determinante en la implementación de la zonificación. En este sentido, se considera como una limitación para este estudio la carencia de información acerca del seguimiento de las epizootias como amenaza de transmisión de fiebre amarilla en áreas endémicas y la cobertura de vacunación antiamarílica como nivel de vulnerabilidad de la población humana. Por último, se sugiere que en trabajos posteriores se articule la perspectiva de las ciencias sociales, la cual permite la inclusión de las amenazas en la percepción de las poblaciones humanas para abordar la construcción del riesgo por parte de los actores sociales y en la diferenciación socioespacial de las vulnerabilidades. Los puntos de intersección entre planteamientos y métodos de las ciencias naturales y sociales podrían potenciar la integración y complementación de la geografía como ciencia transversal, haciendo posible comprender de una forma más amplia el riesgo en función de las amenazas y las vulnerabilidades ${ }^{(7)}$.

\section{REFERENCIAS BIBLIOGRÁFICAS}

1. Íñiguez Rojas L. Geografía y salud en Cuba: tendencias y prioridades. Revista Cubana de Salud Pública. 2003;29(4):0-0.

2. Íñiguez Rojas L. Geografía y salud: temas y perspectivas en América Latina. Cadernos de Saúde Pública. 1998;14(4):701-711.

3. Koch T. Social epidemiology as medical geography: back to the future. GeoJournal. 2009;74(2): 99-106.

4. Barcellos C. Unidades y escalas en los análisis espaciales en salud. Revista Cubana de Salud Pública. 2003;29(4):0-0.

5. Sáez Sáez V, Sejias M, Montezuma D, Paublini $\mathrm{H}$. Estudio preliminar sobre la distribución es- pacial del riesgo epidemiológico de la fiebre amarilla selvática, municipio Jesús María Semprún, estado Zulia, Venezuela. Boletín de Malariología y Salud Ambiental. 2007;47(1):71-82.

6. Parra-Henao GJ. Sistemas de información geográfica y sensores remotos. Aplicaciones en enfermedades transmitidas por vectores. CES Medicina. 2010;24(2):75-89.

7. Coy M. Los estudios del riesgo y de la vulnerabilidad desde la geografía humana. Su relevancia para América Latina. Población y Sociedad. 2010;(17):9-28.

8. Rincón-Romero ME, Londoño JE. Mapping malaria risk using environmental and anthropic variables. Revista Brasileira de Epidemiologia. 2009;12(3):338-354. 
9. Méndez JA, Parra É, Neira M, Rey GJ. Detección por reacción en cadena de la polimerasa de transcriptasa inversa del virus de la fiebre amarilla en monos silvestres: una herramienta sensible para la vigilancia epidemiológica. Biomédica. 2007;27(3):461-467.

10. Rodríguez R. Estrategias para el control del dengue y del Aedes aegypti en las Américas. Revista Cubana de Medicina Tropical. 2002;54(3):189-201.

11. Segura AM, Cardona D, Garzón MO. Tendencias de la mortalidad por fiebre amarilla, Colombia, 1998-2009. Biomédica. 2012;33:52-62.

12. Ruiz-De-Chavez $M$, Jimenez-Aguado $R$, Marquez-Laposse M, Alleyne GAO. Salud y Turismo. Salud Pública de México. 1994;36(1):61-69.

13. Oficina de Naciones Unidas contra la Droga y el Delito. Colombia Censo de Cultivos de Coca 2011 [Internet]. Bogotá: Oficina de las Naciones Unidas contra la Droga y el Delito; 2012 [citado 20 jul 2016]. Disponible en: https://tinyurl.com/ yad6lf3j

14. Velandia MP. Fiebre amarilla y su control en Colombia 2002-2003. Infectio. 2004;8(3):210-219.

15. Sacristán F. Construyendo agenda 21 para el Municipio de la Macarena: una construcción colectiva para el desarrollo sostenible de la Amazonia Colombiana [Internet]. Bogotá: Instituto Amazónico de Investigaciones Científicas - Sinchi; 2007 [citado 20 jul 2016]. Disponible en: https:// tinyurl.com/ybqknuub.

16. Colombia, Concejo Municipal de la Macarena. Acuerdo 16 [Internet]. La Macarena: Alcaldía La Macarena; 2012 [citado 20 jul 2016]. Disponible en: https://tinyurl.com/yceloh8n.

17. Tobón Quintero GJ, Restrepo Gl. Erradicación de cultivos ilícitos y desplazamiento forzado en el parque natural Sierra de la Macarena. Cuadernos de Desarrollo Rural. 2009;6(63):107-138.

18. Alcaldía La Macarena. Diagnóstico general del Municipio La Macarena 2008. La Macarena: Alcaldía La Macarena; 2008.

19. Secretaría de Planeación La Macarena. Acuerdo 020 de 19 de julio de 2002: esquema de ordenamiento territorial de La Macarena. La Macarena: Alcaldía La Macarena; 2002.

20. Oficina de Naciones Unidas contra la Droga y el Delito, Embajada de la República Federal de Alemania, Ministerio de Defensa Nacional República de Colombia. Transformación socioeconómica y biofísica asociadas con cultivos ilícitos en la región
Sur del Meta-Guaviare 1990-2009 [Internet]. Bogotá: Oficina de las Naciones Unidas contra la Droga y el Delito; 2010 [citado 20 jul 2016]. Disponible en: https://tinyurl.com/ycablyez.

21. Rojas Álvarez DP. Situación de la fiebre amarilla en Colombia. Informe Quincenal Epidemiológico Nacional. 2008;13(7):97-109.

22. Instituto de Hidrología, Meteorología y Estudios Ambientales; Instituto Geográfico Agustín Codazzi; Instituto de Investigación de Recursos Biológicos Alexander von Humboldt; Instituto de Investigaciones Marinas y Costeras José Benito Vives De Andréis; Instituto Amazónico de Investigaciones Científicas Sinchi; Instituto de Investigaciones Ambientales del Pacífico Jhon von Neumann. Ecosistemas continentales, costeros y marinos de Colombia. Bogotá: Imprenta Nacional de Colombia; 2007.

23. Oficina de Naciones Unidas contra la Droga y el Delito. Cultivos de coca: estadísticas municipales censo 31 de diciembre de 2010 [Internet]. Bogotá: Oficina de las Naciones Unidas contra la Droga y el Delito; 2011 [citado 20 jul 2016]. Disponible en: https://tinyurl.com/yavhrak4.

24. Oficina de Naciones Unidas contra la Droga y el Delito. Colombia monitoreo de cultivos de coca 2012 [Internet]. Bogotá: Oficina de las Naciones Unidas contra la Droga y el Delito; 2013 [citado 20 jul 2016]. Disponible en: https://tinyurl.com/ ycoraame.

25. Oficina de Naciones Unidas contra la Droga y el Delito. Colombia monitoreo de cultivos de coca 2013 [Internet]. Bogotá: Oficina de las Naciones Unidas contra la Droga y el Delito; 2014 [citado 20 jul 2016]. Disponible en: https://tinyurl.com/ yddkjpaj.

26. ESRI. ArcGIS desktop: release 10 [Internet]. Redlands: Environmental Systems Research Institute; 2011 [citado 20 jul 2016]. Disponible en: https://www.esri.com/es-es/home

27. Niño L. Uso de la función semivariograma y estimación kriging en el análisis espacial de un indicador entomológico de Aedes aegypti (Diptera: Culicidae). Biomédica. 2008;28(4):578-586.

28. Niño L. Interpolación espacial de la abundancia larval de Aedes aegypti para localizar focos de infestación. Revista Panamericana de Salud Pública. $2011 ; 29(6): 417$.

29. Jentes ES, Poumerol G, Gershman MD, Hill DR, Lemarchand J, Lewis RF, et al. The revised global yellow fever risk map and recommendations for vaccination, 2010: consensus of the In- 
formal WHO Working Group on geographic risk for yellow fever. The Lancet Infectious Diseases. 2011;11(8):622-632.

30. Eisen RJ, Eisen L. Spatial modeling of human risk of exposure to vector-borne pathogens based on epidemiological versus arthropod vector data. Journal of Medical Entomology. 2008;45(2):181-192.

31. Vignolles C, Lacaux JP, Tourre YM, Bigeard G, Ndione JA, Lafaye M. Rift Valley fever in a zone potentially occupied by Aedes vexans in Senegal: dynamics and risk mapping. Geospatial Health. 2009;3(2):211-220.

32. Briand S, Beresniak A, Nguyen T, Yonli T, Duru G, Kambire C, et al. Assessment of yellow fever epidemic risk: an original multi-criteria modeling approach. PLoS Neglected Tropical Diseases. 2009;3(7):e483.

\section{FORMA DE CITAR}

Niño L. La zonificación del riesgo en salud: la fiebre amarilla desde una perspectiva geográfica en La Macarena, departamento del Meta, Colombia. Salud Colectiva. 2018;14(1):19-32. doi: 10.18294/sc.2018.1087

Recibido: 4 de agosto de 2016 | Versión final: 5 de abril de 2017 | Aprobado: 14 de junio de 2017

Este obra está bajo una licencia de Creative Commons Reconocimiento-NoComercial 4.0 